\title{
Baseline inflammation is not predictive of periprocedural troponin elevation after elective percutaneous coronary intervention
}

\begin{abstract}
High-sensitivity C-reactive protein predicts future cardiovascular events in both healthy individuals and patients with unstable and stable coronary syndromes. Few data are available about the incidence and the relation to inflammation of troponin elevation following percutaneous coronary intervention (PCI), a potential predictor of longterm outcome. We sought to confirm the impact of embolization on long-term outcome and evaluate the ability of baseline inflammation to predict troponin elevation induced by PCI. We prospectively analyzed 200 patients treated by PCI for stable or Braunwald IIA class unstable angina. The patients were recruited between January 1997 and May 1999, and the population was followed during a mean follow-up of 32 months. Major adverse cardiac events (MACEs) were defined as the occurrence of death, myocardial infarction or recurrent angina requiring repeat PCI, or coronary artery bypass grafting. During the follow-up period, 58 MACEs were observed. By multivariate analysis, independent predictors for the occurrence of MACEs were unstable angina and troponin I level after PCI $(P<0.0001$ for both). No correlation was found between baseline inflammation and significant troponin I elevation post PCI and by multivariate analysis, no biological variable was a predictor of troponin I elevation post PCI. Baseline inflammation cannot predict onset of minor myonecrosis damage (expressed by troponin elevation) induced by PCI, a significant predictor of long-term outcome in this setting.
\end{abstract}

O. Gach $(\bowtie) \cdot$ O. Louis $\cdot$ L.A. Pierard $\cdot$ V. Legrand

Service de Cardiologie, Centre Hospitalier Universitaire du Sart

Tilman, Domaine Universitaire du Sart Tilman (B 35), 4000 Liège 1, Belgium

Tel. +32-4-366-7192; Fax +32-4-366-7837

e-mail: oliviergach@swing.be

J.P. Chapelle

Service de Chimie Médicale, Centre Hospitalier Universitaire du Sart Tilman, Domaine Universitaire du Sart Tilman (B 35), Liège, Belgium

S. Vanbelle

Institut de Biostatistique, Université de Liège, Liège, Belgium
Key words Inflammation - Embolization - Percutaneous coronary intervention

\section{Introduction}

Among various studied inflammatory markers, ${ }^{1}$ high-sensitivity C-reactive protein is an inflammatory marker that predicts future cardiovascular events in both healthy individuals with no history of cardiovascular disease and in patients with unstable as well as stable coronary syndromes. ${ }^{2-5}$ Preprocedural high-sensitivity C-reactive protein has been found to be an independent predictor of adverse cardiac events in patients treated by elective percutaneous coronary intervention (PCI) with or without a stent ${ }^{6,7}$ as well as in patients treated by surgical revascularization. ${ }^{8}$ Inflammatory reactivity has been found to be a powerful predictor of complication in stable angina treated by PCI. ${ }^{9}$

Troponin elevation in the setting of elective intervention has been linked to higher mortality in several clinical settings. ${ }^{10-12}$ Except for local anatomic characteristics ${ }^{13}$ (i.e., side branch, degree of atheroma burden, evidence of thrombus in angiography), the predisposing factors that lead to periprocedural minor myonecrosis are not fully established. Especially, it is unknown if arterial inflammation and heightened inflammatory state could favor embolization and could be responsible for short- or long-term complications. Enhanced inflammatory activity could be able to favor myocardial damage by various mechanisms (facilitating local recruitment of inflammatory cells, altering small vessel function, destabilizing coronary plaque, promoting endothelial activation by a decreased nitric oxide bioavailability). Despite these different theoretical mechanisms, the inter-relationship between these two parameters is not fully understood. The purposes of this study were to evaluate the long-term prognostic impact of embolization in patients treated by PCI and afterward analyze the relation between baseline inflammation and postprocedural troponin I elevation. 


\section{Patients and methods}

\section{Patients}

Between January 1997 and May 1999, we prospectively analyzed 200 patients referred for coronary angioplasty for stable or Braunwald class IIa unstable angina. They underwent PCI of one or more coronary stenoses. The exclusion criteria were patients with suspected or confirmed acute coronary syndrome (with or without ST segment elevation) at presentation or within 6 months, patients treated for restenosis, total occlusion or coronary graft, coronary artery bypass grafting, or PCI within 6 months, heart failure in New York Heart Association class $\geq 3$, abnormal renal function, or known malignant or inflammatory disorders. Follow-up was obtained in all patients by inspection of the medical records. Major adverse cardiac events (MACEs) were defined as the occurrence of death of any cause, myocardial infarction (with or without ST segment elevation), and any coronary revascularization (surgery and/or percutaneous). Myocardial infarction was defined as the occurrence of typical chest pain associated with an increase of creatine kinase-MB at least three times above the upper normal limit or with the development of new pathological $\mathrm{Q}$ waves on the electrocardiogram. All patients have given their informed consent and the study was approved by the local ethics committee.

\section{Blood sampling}

A fasting morning blood sample was taken from each patient on the day before and $24 \mathrm{~h}$ after the angioplasty. High-sensitivity C-reactive protein assays were measured by rate nephelometry using a commercially available kit (Behring N latex C-reactive protein mono Analyzer, Behring Diagnostic, Marburg, Germany). The lower detection limit was $0.175 \mathrm{mg} / \mathrm{l}$. Troponin I assays were measured by a commercial microparticle enzyme immunoassay kit (AxSYM Abbott Laboratories, Abbott Park, IL, USA). The normal value is $\leq 0.5 \mu \mathrm{g} / \mathrm{l}(n=437)$.

\section{Coronary angiography}

Selective coronary angiography was performed via the femoral route using a 6-F introducer sheath. Serial coronary angiograms of the left and right coronary arteries were performed after intracoronary administration of isosorbide dinitrate (0.2-0.4 mg). After diagnostic evaluation, angioplasty with or without stenting was performed. Heparin $(70 \mathrm{U} / \mathrm{kg}$ ) was given before the introduction of the guide wire. No patient received glycoprotein IIb/IIIa inhibitors, but all were pretreated with ticlopidine $(500 \mathrm{mg})$ at least $4 \mathrm{~h}$ before intervention. All patients were treated with aspirin indefinitely and ticlopidine $250 \mathrm{mg}$ twice daily was added for 4 weeks in the patients treated by stenting.
Statistical analysis

Results are expressed as mean \pm standard deviation (SD) for quantitative variables while frequencies and proportions (\%) were used for categorical variables. Mean values were compared by the Student $t$-test (for normally distributed variables) and by the Wilcoxon test otherwise. Proportions were compared by the chi-squared test for contingency tables. Cox proportional hazards regression analysis was used to test the effect of covariates on major adverse cardiac event-free interval and to derive hazard ratio (HR) with $95 \%$ confidence interval (95\% CI). Multivariate logistic regression was used to detect clinical and/or biological predictor factors of significant troponin I elevation. Odds ratio (OR) with $95 \%$ CI were also given. Results were considered significant at the $5 \%$ critical level $(P<0.05)$. All calculations were performed using SAS (version 9.1 for Windows; SAS Institute, Cary, NC, USA) and S-PLUS (version 6.2; Insightful, Seattle, WA, USA) statistical packages.

\section{Results}

The clinical and biological characteristics of the studied population are listed in Table 1. Mean baseline highsensitivity C-reactive protein levels were $4.21 \pm 5.80 \mathrm{mg} / \mathrm{l}$ and were higher in smokers (4.29 \pm 5.02 vs $4.06 \pm 7.03 \mathrm{mg} / \mathrm{l}$, $P=0.048)$ and in patients with unstable angina $(5.42 \pm$ 6.24 vs $4.06 \pm 5.73 \mathrm{mg} / \mathrm{l}, P=0.044)$. Baseline leukocyte count was higher in current smokers $(7.74 \pm 2.06$ vs $6.89 \pm$ $\left.1.7010^{3} / \mathrm{mm}^{3}, P=0.0018\right)$ while baseline fibrinogen was higher in diabetic patients $(3.35 \pm 0.80$ vs $2.96 \pm 0.70 \mathrm{~g} / \mathrm{l}$, $P=0.014)$.

Table 1. Clinical and biological characteristics of the studied population

\begin{tabular}{lcc}
\hline Variable & $n=200$ & \\
\cline { 2 - 3 } & Pre-PCI & Post-PCI \\
\hline Men & $161(80.5 \%)$ & \\
Age (years) & $64 \pm 9.6$ & \\
Current smoker & $130(65 \%)$ & \\
Hypertension & $106(53 \%)$ & \\
Hyperlipidemia & $98(49 \%)$ & \\
Diabetes mellitus & $31(15.5 \%)$ & \\
Stable angina & $178(89 \%)$ & \\
Ejection fraction $<60 \%$ & $47(23.5 \%)$ & \\
Stent & $103(51.5 \%)$ & \\
Statin treatment & $31(15.6 \%)$ & $175(87.5 \%)$ \\
Total cholesterol $(\mathrm{mg} / \mathrm{dl})$ & $225 \pm 44$ & $212 \pm 46$ \\
Triglycerides $(\mathrm{mg} / \mathrm{dl})$ & $192 \pm 14$ & $214 \pm 13$ \\
hsCRP $(\mathrm{mg} / \mathrm{l})$ & $4.21 \pm 5.8$ & $8.29 \pm 9.6$ \\
White blood count $\left(10^{3} / \mathrm{mm}^{3}\right)$ & $7.45 \pm 1.98$ & \\
Fibrinogen $(\mathrm{g} / \mathrm{l})$ & $3.01 \pm 0.73$ & $3.22 \pm 0.65$ \\
Creatine kinase $\mathrm{MB}(\mu \mathrm{g} / \mathrm{l})$ & $2.29 \pm 1.32$ & $8.3 \pm 16$ \\
Troponin I $(\mu \mathrm{g} / \mathrm{l})$ & $0.22 \pm 0.61$ & $2.33 \pm 6.7$ \\
\hline Values & &
\end{tabular}

$\overline{\text { Values expressed as mean } \pm \text { SD for age and as mean } \pm \text { SEM for other }}$ values

hsCRP, high-sensitivity C-reactive protein; PCI, percutaneous coronary intervention 
Table 2. Independent predictive factors of MACEs in multivariate analysis

\begin{tabular}{|c|c|c|c|c|}
\hline & \multicolumn{2}{|c|}{ Univariate analysis } & \multicolumn{2}{|c|}{ Multivariate analysis } \\
\hline & $P$ value & Hazard ratio $(95 \% \mathrm{CI})$ & $P$ value & Hazard ratio $(95 \% \mathrm{CI})$ \\
\hline Unstable angina & $<0.0001$ & $5.96(3.42-10.38)$ & $<0.0001$ & $6.58(3.43-12.6)$ \\
\hline Statin treatment & 0.03 & $1.20(0.61-2.37)$ & NS & \\
\hline Troponin I post PCI & $<0.0001$ & $1.08(1.04-1.11)$ & $<0.0001$ & $1.10(1.05-1.15)$ \\
\hline
\end{tabular}

MACEs, major adverse cardiac events; PCI, percutaneous coronary intervention; CI, confidence interval; NS, not significant

Mean baseline troponin I was $0.22 \pm 0.61 \mu \mathrm{g} / \mathrm{l}$, that it is to say within normal range (normal value $\leq 0.5 \mu \mathrm{g} / \mathrm{l}, n=437$ ) while post intervention mean values were $2.33 \pm 6.7 \mu \mathrm{g} / \mathrm{l}$. Patients treated with stent presented higher postintervention troponin I levels $(3.58 \pm 8.90$ vs $1.01 \pm 2.41 \mu \mathrm{g} / \mathrm{l}$, $P=0.0002)$. Forty-four patients (22\%) presented more than threefold elevation of troponin I after intervention. Those patients presented higher baseline troponin I levels $(0.58 \pm$ 1.02 vs $0.12 \pm 0.37 \mu \mathrm{g} / \mathrm{l}, P<0.0001)$ while their baseline C-reactive protein levels were higher but without reaching statistical significance $(5.85 \pm 8.88$ vs $3.76 \pm 4.53 \mu \mathrm{g} / \mathrm{l}$, $P=0.87$ ).

During the follow-up period (mean $=30.8 \pm 16.1$ months), $29 \%$ of the studied population presented a major cardiac adverse event: 9 patients died, 12 patients presented acute myocardial infarction (2 Q-wave, 10 non-Q Wave), 5 patients underwent coronary artery bypass grafting for recurrent ischemia, 13 patients were treated by PCI on another lesion than the initial one, and 26 patients presented angiographic restenosis in whom 19 were treated by repeat PCI.

In multivariate analysis, the predictors of MACEs were unstable angina (HR: 6.58 [3.43-12.6]) and troponin I post intervention (HR: 1.10 [1.05-1.15]) (Table 2). No relation was found between baseline high-sensitivity C-reactive protein levels and significant elevation of troponin I induced by PCI (up to threefold the normal values). Neither was baseline C-reactive protein level correlated to delta troponin, defined as troponin I level post PCI minus troponin I pre PCI.

By multivariate analysis, the only predictor of significant troponin I elevation post intervention was stent implantation (OR: 2.78 [1.18-6.56]). None of the studied biological parameters including especially baseline high sensitivity Creactive protein $(P=0.53)$ were predictors of troponin I elevation.

\section{Discussion}

In our study, as in previously published reports, we report a significant prognostic impact of troponin I elevation after intervention on long-term outcome..$^{10,11,14,15}$. These troponin elevations may be in part closely related the procedure (embolization and/or closure of side branch). Unfortunately, even careful angiographic assessment cannot completely predict which patients will develop periprocedural embolization responsible for microvascular obstruction and necrosis. Moreover, detection of such a predisposing situation can only be made in the catheterization laboratory, ruling out the possibility of preinvasive optimal pharmacological preparation. Lesion morphology provides some prognostic information particularly in regard to the procedure-related risk but troponin is a more powerful predictor of cardiac risk than angiographic characteristics. ${ }^{16}$

Nevertheless, underlying predisposing factors that lead to minor periprocedural myocardial infarction could also play a role. ${ }^{17,18}$ Systemic and arterial inflammation favoring embolization is one of these potential predisposing factors that would be available prior to the catheterization laboratory. In this hypothesis, baseline C-reactive protein levels should be able to predict significant troponin elevation post intervention. Contrary to Saadeddin et al., ${ }^{19}$ we failed in this study to demonstrate this predictive ability of baseline inflammation. In this previous report, which included a limited number of patients $(n=85)$, the authors used an arbitrary cutoff level of high-sensitivity C-reactive protein that was quite elevated $(6 \mathrm{mg} / \mathrm{l})$ to define significant enhanced inflammation status.

Periprocedural myonecrosis predicts outcome although the exact threshold is undetermined, varying across studies. Therapies liable to reduce such minor necrosis also reduce long-term complications. ${ }^{20-22}$ In the ARMYDA study ${ }^{20}$ pretreatment with Atorvastatin, a drug with known antiinflammatory properties, ${ }^{23}$ significantly reduced procedural myocardial injury in an elective population but this effect was observed while $\mathrm{C}$-reactive protein levels at the time of procedure were not significantly different in the two groups. Periprocedural myonecrosis appears therefore as a target for therapy, and a preinvasive indicator of the susceptibility of subsequent event would be of great interest. In our report, baseline inflammation does not demonstrate this property.

Stents usually lead to some degree of embolization, more frequently than does balloon angioplasty. ${ }^{24}$ This observation is confirmed in this study.

\section{Study limitations}

Although the data were collected prospectively, this is a retrospective single-center analysis and is subject to the limitations of such analysis. This study involves a limited population with a relatively short follow-up. No drug-eluting stents were used. Our observations are not necessarily applicable to other clinical settings. Platelet function was not evaluated and therefore it is impossible to exclude that 
some patients could present aspirin resistance, a factor known to promote periprocedural myonecrosis.

\section{Conclusions}

Periprocedural minor myocardial necrosis is a frequent observation in this study. The troponin release occurring after PCI is an independent predictive factor of outcome. The predisposing factors that lead to periprocedural minor myonecrosis are not fully established. In this study, baseline inflammation assessed by high-sensitivity C-reactive protein measurement is not able to predict the occurrence of such troponin release corresponding to embolization.

\section{References}

1. Chen MC, Chen CJ, Yang CH, Wu CJ, Fang CY, Hsieh YK, Chang HW (2007) Interleukin-18: a strong predictor of the extent of coronary artery disease in patients with unstable angina. Heart Vessels 22:371-375

2. Ridker PM, Rifai N, Rose L, Buring JE, Cook NR (2002) Comparison of C-reactive protein and low-density lipoprotein cholesterol levels in the prediction of first cardiovascular events. $\mathrm{N}$ Engl J Med 347(20):1557-1565

3. Ridker PM, Hennekens CH, Buring JE, Rifai N (2000) C-reactive protein and other markers of inflammation in the prediction of cardiovascular disease in women. N Engl J Med 342:836-843

4. Liuzzo G, Biasucci LM, Gallimore JR, Grillo RL, Rebuzzi AG, Pepys MB, Maseri A (1994) The prognostic value of C-reactive protein and serum amyloid a protein in severe unstable angina. $\mathrm{N}$ Engl J Med 331:417-424

5. Zebrack JS, Muhlestein JB, Horne BD, Anderson JL (2002) Creactive protein and angiographic coronary artery disease: independent and additive predictors of risk in subjects with angina. J Am Coll Cardiol 39:632-637

6. Buffon A, Liuzzo G. Biasucci LM, Pasqueletti P, Ramazzotti V, Rebuzzi AG, Crea F, Maseri A (1999) Preprocedural serum levels of C-reactive protein predict early complications and late restenosis after coronary angioplasty. J Am Coll Cardiol 34:1512-1521

7. Gaspardone A, Crea F, Versaci F, Tomai F, Pellegrino A, Chiarello L, Gioffre PA (1998) Predictive value of C-reactive protein after successful coronary-artery stenting in patients with stable angina. Am J Cardiol 82:515-518

8. Gaspardone A, Ciavolella M, Carlizzi G, Xagoraris V, Romeo F, Gioffré PA (1982) Determinazione della proteina C-reattiva in cardiochirurgia: importanza nel monitoraggio post-operatorio delle complicanze. Cardiologia 27:1121-1132

9. Gach O, Legrand V, Biessaux Y, Chapelle JP, Vanbelle S, Pierard LA (2007) Long-term prognostic significance of high-sensitivity C-reactive protein before and after coronary angioplasty in patients with stable angina pectoris. Am J Cardiol 99:31-35

10. Herrmann J, Von Birgelen C, Haude M, Volbracht L, Malyar N, Eggebrecht H, Konorza TF, Baumgart D, Erbel R (2002) Prognostic implication of cardiac troponin $\mathrm{T}$ increase following stent implantation. Heart 87:549-553
11. Nallamothu BK, Chetcuti S, Mukherjee D, Grossman PM, KlineRogers E, Werns SW, Bates ER, Moscucci M (2003) Prognostic implication of troponin I elevation after percutaneous coronary intervention. Am J Cardiol 91:1272-1274

12. Cavallinin C, Savonitto S, Violini R, Arraiz G, Plebani M, Olivari Z, Rubartelli P, Battaglia S, Niccoli L, Steffenino, Ardissino D (2005) Impact of the elevation of biochemical markers of myocardial damage on long-term mortality after percutaneous coronary intervention: results of the CK-MB and PCI study. Eur Heart J 26:1494-1498

13. Bhatt DL, Topol EJ. Does creatinine kinase-MB elevation after percutaneous coronary intervention predict outcomes in 2005? (2005) Circulation 112:906-915

14. Abdelmeguid AE, Topol EJ, Whitlow PL, Sapp SK, Ellis SG (1996) Significance of mild transient release of creatine kinase-MB fraction after percutaneous coronary interventions. Circulation 94:1528-1536

15. Prasad A, Singh M, Lerman A, Lennon RJ, Holmes DR, Rihal CS (2006) Isolated elevation in cardiac troponin $\mathrm{T}$ after percutaneous coronary intervention is associated with higher long-term mortality. J Am Coll Cardiol 48:1765-1770

16. Heeschen C, Vanden Brand M, Hamm CW, Simoons ML (1999) Angiographic findings in patients with refractory unstable angina according to troponin T status. Circulation 104:1509-1514

17. Bhatt DL, Topol EJ (2002) Need to test the arterial inflammation hypothesis. Circulation 106:136-140

18. Chew DP, Bhatt DL, Robbins MA, Penn MS, Schneider JP, Lauer MS, Topol EJ, Ellis SG (2001) Incremental prognostic value of elevated baseline C-reactive protein among established markers of risk in percutaneous coronary intervention. Circulation 104: 992-997

19. Saadeddin SH, Habbab MA, Sobki SH, Ferns GA (2002) Association of systemic inflammatory state with troponin I elevation after elective uncomplicated percutaneous coronary intervention. Am J Cardiol 89:981-983

20. Pasceri V, Patti G, Nusca A, Pristipino C, Richichi G, Di Sciascio G (2004) Randomized trial of atorvastatin for reduction of myocardial damage during coronary intervention: results from the ARMYDA (Atorvastatin for Reduction of MYocardial Damage during Angioplasty) study. Circulation 110:674-678

21. Sharma SK, Kini A, Marmur JD, Fuster V (2000) Cardioprotective effect of prior beta-blocker therapy in reducing creatine kinaseMB elevation after coronary intervention: benefit is extended to improvement in intermediate-term survival. Circulation 102:166172

22. Tardiff BE, Califf RM, Tcheng JE, Lincoff AM, Sigmon KN, Harrington RA, Mahaffey KW, Ohman EM, Teirstein PS, Blankenship JC, Kitt MM, Topol EJ (1999) Clinical outcomes after detection of elevated cardiac enzymes in patients undergoing percutaneous intervention. IMPACT-II Investigators. Integrilin (eptifibatide) to Minimize Platelet Aggregation and Coronary Thrombosis-II. J Am Coll Cardiol 33:88-96

23. Oka H, Ikeda S, Koga S, Miyahara Y, Kohno S (2008) Atorvastatin induces associated reductions in platelet P-selectin, oxidized lowdensity lipoprotein, and interleukin-6 in patients with coronary artery diseases. Heart Vessels 23:249-256

24. Iakovou I, Mintz GS, Dangas G, Abizaid A, Mehran R, Kobayashi Y, Lansky AJ, Aymong ED, Nikolsky E, Stone GW, Moses JW, Leon MB. (2003) Increased CK-MB release is a "trade-off" for optimal stent implantation: an intravascular ultrasound study. J Am Coll Cardiol 42:1900-1905 